\title{
Mis on rituaalne aasta? Küsimus ja vastused
}

Emily Lyle

\begin{abstract}
Teesid: Rituaalse aasta olemuse kohta pole seni üldkehtivat teooriat. Seda võib vaadelda kui põllundus- või karjandus-, aga ka kui astronoomilist aastat. Minu lähenemise aluseks on analoogiad ja ma pean inimese eluringi aastajaotusmudelite mõistmisel esmatähtsaks. Kasutan heuristilise töövahendina etalonsüsteemi ning võrdlen aastat ja ööpäeva, nagu seda on teinud ka vene uurija Nikita Tolstoi. Ööpäev jaguneb päevaks ja ööks, aasta suveks ja talveks. Päev ja öö ning suvi ja talv on polaarsed opositsioonid. Varasemates uurimustes olen ma seda opositsiooni nimetanud B-telje polaarsuseks, kusjuures päev ja suvi jäävad positiivsele poolele. Samasugust jaotust saame kasutata ka kuufaaside puhul. Neid mudelid iseloomustab range isomorfism. See viib analoogiani George Dumézili inimelu käsitluse funktsioonide triaadiga (füüsiline jõud, õitseng ja pühadus).
\end{abstract}

Märksõnad: eluring, isomorfism, kuufaasid, rituaalne aasta, suvine poolaasta, talvine poolaasta, ööpäev

Alustades ühisuurimust Rahvusvahelise Etnoloogia ja Folkloori Ühingu (Société Internationale d'Ethnologie et de Folklore = SIEF) rituaalse aasta töörühmas, näib olulisem kui kunagi varem võtta vaatluse alla rituaalse aasta olemus ja identiteedi põhiküsimused. Meil on suurepärane võimalus heita pilk erinevates Euroopa kultuurides kasutusel oleva kombestiku rikkalikele varjunditele ning vaadelda neid folkloori ja etnoloogia üldisemate põhimõtete valguses. Samas aga läheb see meie töörühma olemasolust johtuv unikaalne võimalus kaduma, kui me ei aseta oma mikrouurimusi laiemasse raamistikku, milleks on antud juhul üldisem arusaam rituaalse aasta olemusest. Minu arvates puudub meil nendes küsimustes praegu üksmeel. See on enesestmõistetav, sest uurijad on siiani tegelnud väga erinevate teemadega ja vaadelnud neid väga erinevatest vaatenurkadest. Kuid meil on siin nüüd foorum ja foorum ongi mõeldud vaidlemiseks ja mõttevahetuseks. Mõnikord hoiduvad uurijad - võibolla viisakusest - üksteise vaadetega haardumast ja räägivad üksteisest mööda. Ja mõnikord (ma olen märganud, et see kehtib eriti just varasemate ri- 
tuaalset aastat puudutavate uurimuste kohta) väljendavad nad end liialt sõjakalt, mis tekitab pigem pingeid kui selgust. Meil on ees veel liialt palju tööd, et sellistele suhtlemisviisidele aega raisata. Tõeline mõttevahetus on palju produktiivsem, sest see kutsub iga osalejat üles oma algseid seisukohti kriitiliselt üle vaatama, neid lähemalt selgitama ja vajadusel ka muutma.

Mis on rituaalne aasta? Kogu Euroopat on paljude sajandite jooksul mõjutanud kristlik liturgia, mis väärib kahtlemata juba ise lähemat uurimist, kuid kristluse-eelsele kombestikule on sellel olnud selgelt lämmatav mõju. Samas pakub meile erilist huvi omas eheduses just eelkristlik rituaalne aasta, mis osutub eriti hoomamatuks juhtudel, kui üritame seda selgelt määratleda. See on ka põhjus, miks mainisin artikli pealkirjas vastuseid (mitte ühte ja ainuõigest vastust) küsimusele, mis on rituaalne aasta. Ootan mõttevahetust, eeldades, et mõned uurijad võivad tahta rohkem rõhutada põllundus- või karjandus- või astronoomilist aastat või veel mõnda muud lähenemist. Minu lähenemise aluseks on analoogiad ja ma pean inimese eluringi aastajaotusmudelite mõistmisel esmatähtsaks. Peatun sellel seisukohal allpool pikemalt.

Lisaks sellele võib tõusetuda küsimus, kas on võimalik üldse eristada mingit ühtset sidusat põhimudelit, ja kui on, siis milline ajalooline ja geograafiline kontekst hõlmab seda kõige täielikumalt. Nendele küsimustele on sõltuvalt uurimisel kasutatavast mõõtkavast mitmeid vastuseid. Uurijatel on täiesti lubatud uurida kalendriliste rituaalide tsüklit näiteks ühe riigi piires või siis ühe linna, kihelkonna, küla, asutuse, majapidamise või isikukogemuse piires. Usutavasti leiame, et igasugused potentsiaalsed ebakõlad, mille uurija suudab avastada, on sageli suudetud kogukonna või indiviidi tasandil kõrvaldada ja selles võib täheldada teatavat sidusust. Kui ebakõlad säilivad, saab neist tõenäoliselt poliitiliste või religioossete pingete keskpunkt, mistõttu teatud aastaringi perioodid võivad olla potentsiaalselt eriti plahvatusohtlikud ning see peaks meile meelde tuletama asjaolu, et meie vagurad teaduslikud püüdlused võivad mõnikord tähendada mängu püssirohuga. Kuigi pole lootust, et suudame lühemas perspektiivis leevendada maailmavaate erinevustest ning rikkuse ja võimuga seotud lisateguritest tingitud pingeid, olen ma piisavalt naiivne uskumaks, et pikemas perspektiivis suudame me anda olulise panuse inimkonna eneseteadvusesse ja võimesse eristada ühiselemente, mis muudavad inimkonna väärtussüsteemi tervikuna sidusaks.

Selleks, et edukalt edasi liikuda, peame heitma korraks pilgu tagasi ja täitma tänaseni säilinud tühikud oma kultuuripärimuses. Arvan, et oleme läbi teinud kultuuripõhise valikulise unustamise ja meid pole julgustatud esitama neid kaugeleulatuvaid küsimusi, mis praegu nii pakiliselt vastuseid ootavad. Miks ei leidu ühtegi kehtivat tunnustatud teooriat rituaalse aasta kohta? Võib-olla on siin inimesi, kes väidavad, et selline teooria on olemas ja mul 
oleks hea meel sellest kuulda ning sealt oma arutelu jätkata. Ent tundub, et üks valdkondadest, mida meil tuleb lähemalt vaadelda, on mõttelugu alates 18. sajandist, eriti aga viimase saja aasta raamesse jäävad ideed. Need tunduvad meile ajaliselt nii lähedal, et mõned uurijad määratlevad antud valdkonda ikka veel pelgalt vastureaktsiooni põhjal, eitades kas otseselt või varjatult igasuguse üldkehtiva sidususe võimalikkust. Tundub, et kujunenud olukorras, kus rõhuasetus on kultuuriuurimustel, on uurijatel tihti lihtsam mõtiskleda lähiajaloo üle ajaloolisest aspektist kui keskenduda täiesti värsketele episoodidele, mille kohta tehtavad järeldused tunduvad oma algfaasis ülimalt spekulatiivsed. Rõhutan siinkohal, et ajaloolised uurimused on iseenesest väga teretulnud.

Ma loodan siiski, et mõned uurijad sisenevad ka traditsioonilise kosmoloogia uurimise käigus kujunenud uuele teooriaväljale ja on valmis seda materjali analüüsimisel kasutama. See annaks vajaliku sügavuse ja ulatuse rituaalse aasta uurimisse kui ühele sotsiaalse võrgustiku tahule. Rituaalne aasta on olnud üks paindlikemaid valdkondi ja seda on (või on olnud) võimalik uurida nii kaasaegsete kui varasemate välitööde põhjal, mis tagab küllusliku uurimismaterjali ja annab tunnistust selle vahetust inimlikust väärtusest. Ilma nähtuse juuri tundmata ei suuda me seda siiski täielikult mõista ja et keegi meist ei oska määratleda rituaalse aasta päritolu, tuleb meil loobuda ajaloolistest raamidest ja esitada endale küsimus, kuidas saada informatsiooni eelajaloolise perioodi kohta. Mina seda olen teinud nii, et võtsin aluseks elufaaside (noorus, täisiga ja vanadus) põhistruktuuri nende kolme funktsiooni taustal, mille Georges Dumézil on avastanud indoeurooplasi käsitlevatest ajalooallikatest seoses sõdalaste, maaharijate ja preestrite sotsiaalsete rühmadega. Samas pole diakrooniline uurimismeetod, mis on meie praeguses uurimisstaadiumis paratamatult spekulatiivne, kindlasti ainuke võimalik lähenemisviis. Me saame tegevust koordineerida, võttes kasutusele etalonsüsteemi, mis võimaldab väga erinevaid materjale vaadelda suhestatuna teatud fikseeritud tsükliga. See ei tarvitse olla üldlevinud lähenemisviis. See võib selleks küll saada, kui nii osutub otstarbekaks, kuid selline etalonsüsteem võib iseenesest olla üsna meelevaldne. Me ei pea ette ära otsustama, kas meil õnnestub leida sellele piisavalt toetavat materjali. Tegemist on heuristilise töövahendiga.

Nüüd aga tutvustan mõningaid aspekte oma lähenemisest, mis - nagu juba mainisin - lähtub analoogiatest ja omistab inimese eluringile aastajaotusmudelite mõistmisel võtmerolli. Kuigi analoogia võib hõlmata ajaliselt väga pikki perioode ja käsitleda terveid epohhe või aja kulgu kui sellist suures plaanis ja sekundeid või veel väiksemaid ajaühikuid väikeses plaanis, on põhiliste analoogiasarjade suureks plaaniks inimese elutsükkel, taandudes aastaringi 
käsitlemisel väikesele plaanile, mille väikseim ühik on 24 tunnist koosnev ööpäev. Arvan, et otstarbekas on teadvustada endale kõiki nelja tasandit. Etalonsüsteemi loomisel ootavad meid ees kaks ülesannet. Esiteks, niisuguste üldiste tsükliliste jaotuste juures esinevate mudelitega tutvumine, ja teiseks, nende mudelite liigitamine kategooriatesse. Alustan päeva ja aasta tasandilt, sest mul on rõõm teatada, et nende kohta on nimekas Vene teadlane, Moskva etnolingvistika koolkonna rajaja Nikita I. Tolstoi (1923-1996) analoogiad juba välja töötanud ja oma tulemused publitseerinud. N. Tolstoi käsitleb neid analoogiaid artiklis, mis on ilmunud kõigepealt vene keeles (Tolstoi 1997) ja hiljem ka inglise keeles pealkirja all "The Magic Circle of Time" ajakirjas Cosmos (Tolstoi 2002 [2005]). Võlgnen selle teadmise Irina Sedakovale, kelle 2004. aastal Edinburgh'is Traditsioonilise Kosmoloogia Seltsi rituaalse aasta konverentsil peetud ettekanne toetus nimetatud kirjutisele. See konverents peeti enne meie rituaalse aasta töörühma iga-aastast kokkusaamist.

N. Tolstoi süstematiseerib põhjalikult slaavi kultuurist pärinevaid etnograafilisi andmeid ja esitab need diagrammina, tehes tähelepaneku:

Analü̈̈sides eelnimetatud andmeid tervikuna ei saa meil 24-tunnilise ööpäevatsükli perioodideks jaotamise mudeli ja aasta perioodideks jaotamise mudeli puhul jääda märkamata nende range isomorfism. See isomorfism saab tekitada vaatlejas ainult imetlust... Näeme sellest mudelist, et öö on vastavuses talvega, päev suvega, südä̈ö jõuludega, keskpäev jaanipäevaga, päiksetõus paastumaarjapäevaga ja päikseloojang ristiülendamise päevaga. Keskpäev jagab päeva kaheks ja südaöö jagab öö kaheks. Kogu 24-tunnise ööpäeva jagavad päikesetõus ja päikeseloojang päevaks ja ööks ning täpselt samamoodi jagavad maarjapäev ja ristipäev või siis jüripäev ja dimitripäev aasta kaheks. Erilist huvi pakub nende kahe mudeli puhul isomorfism, mida kohtame ööpäevase tsükli puhul südaööle järgnevate perioodide ja aastaringitsükli puhul jõuludele jörgnevate perioodide puhul (Tolstoi 2002 [2005]).

See on väga kaalukas väide ja ma omakorda kasutan erinevaid lõike sellest, et arendada välja diagramm (joonis 1), mis haakub N. Tolstoi omaga.

Ööpäev jaguneb päevaks ja ööks ning samamoodi jaguneb aasta suveks ja talveks. Peagi näeme, et nende perioodide märkimiseks on otstarbekas kasutada erinevaid värvusi, antud faasis kasutan ma punast (mustvalgel joonisel hall) suvise poolaasta ja valget talvise poolaasta märkimiseks. Päev ja öö ning suvi ja talv on polaarsed opositsioonid. Varasemates uurimustes olen ma seda opositsiooni nimetanud B-telje polaarsuseks (Lyle 1990a), kusjuures päev ja suvi jäävad positiivsele poolele. Päeva ja öö piire märgivad üheselt päikesetõus ja päikeseloojang, seevastu aasta puhul on asi teisiti, sest siin on loodu- 


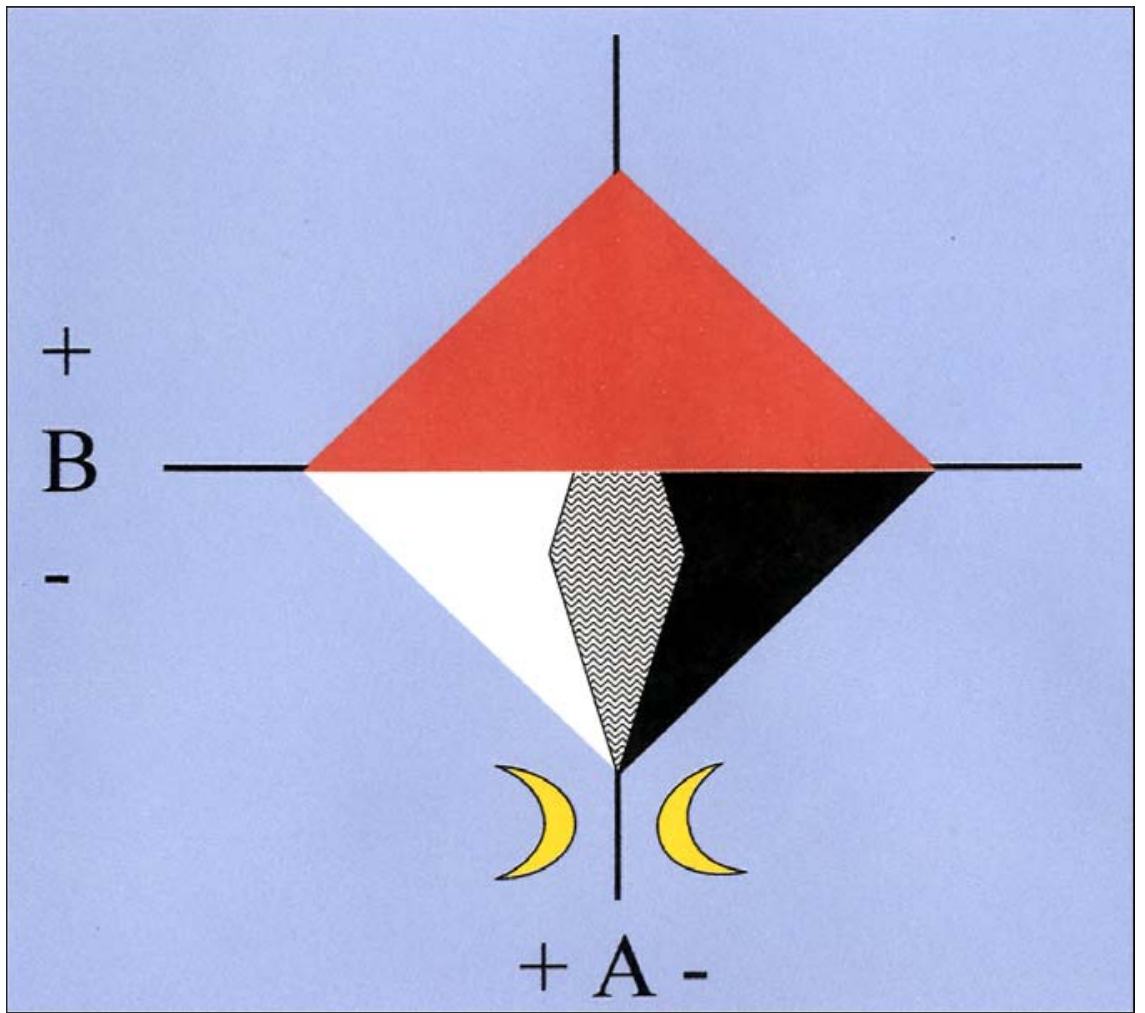

Joonis 1. Aasta ja ööpäeva jagunemine A-ja B-teljel.

sele suve selgel eristamisel talvest toeks kultuur. See selgub ka N. Tolstoi lõppjäreldustest, kus tuuakse alternatiivseid näiteid erinevatest slaavi traditsioonidest: suvine poolaasta kestab kas paastumaarjapäevast (25. märts) kuni ristiülendamise päevani (14. september) või jüripäevast (23. aprill) dimitripäevani (26. oktoober). ${ }^{1}$ Samamoodi avaldas mulle muljet ühe Tartu muuseumi väljapanek, mida ma nägin kolme aasta eest oma külaskäigul Eestisse ja millel kujutati suve kestmist jüripäevast (23. aprill) mihklipäevani (29. september). Toona tundus mulle väga asjakohane ja muljetavaldav, et poolaastate murdepunkte valvavad sõdalastest pühakud. Siiamaani on kõikide ajajaotusmudelite puhul kasutatud kristlikust kalendrist pärit terminoloogiat, kuid N. Tolstoi uurimus ei piirdu ainult sellega. Slaavi kultuuriruumis tuntakse kaht väga selget tähist, mis märgivad aasta poolitumist ja need ei ole kristlusele vähimatki tänu võlgu - üks neist on taevas ning teine maapind ja selle alune. Esimene neist seostub päikesega ja viitab oma kõige äärmuslikumates vormides koguni kahe päikese, nimelt suvepäikese ja talvepäikese olemasolu- 
le, mille vahetumine toimub kristlikust kalendrist tuntud poolaasta vahetumist märkivate pühade ajal. Väidetavalt muudavad nendel päevadel ka maod oma asukohta, minnes talveks maa-alustesse peidukohtadesse talveunne ja tulles suveks uuesti maapinnale. Viimati kuulsin ma kahest päikesest ühel Edinburgh'is peetud konverentsil 2001. aastal, kui Patricia Lysaght tõi iiri kultuurikontekstist rääkides esile uskumuse, mille järgi suur päike on taevas alates Bealtaine'st (1. mai ja selle eelõhtu) kuni Samhainini (1. november ja selle eelõhtu); talvisel poolaastal aga asendab suurt päikest väike päike. Iirimaal ei leidu madusid - väidetavalt kihutas Püha Patrick nad minema -, kuid ühes teises keldi kultuuriruumi piirkonnas, nimelt Galiitsias (Hispaania) peetakse madusid olulisteks kahe perioodi markeriteks, kusjuures suvine poolaasta kestab maist septembri lõpuni, kui maod on liikvel ja ohtlikud, talvine poolaasta aga oktoobrist aprilli lõpuni, kui maod on peidus ja neid pole vaja karta (vt Mandiales-Castro 2004)). ${ }^{2}$ Näeme, et kuigi esineb tugev kalduvus jagada aasta suviseks ja talviseks poolaastaks, on konkreetsed daatumid erinevad. Päev koos oma nähtavate piiritähistega päikesetõusu ja päikeseloojangu näol on B-teljest lähtuva päeva ja aasta analoogias selgemalt avalduv komponent.

N. Tolstoi viitab ka sellele, et keskpäev jagab päeva pooleks ja südaöö jagab öö pooleks, samamoodi nagu jaanipäev (24. juuni, suvine pööripäev) poolitab suve ja jõulud (25. detsember, talvine pööripäev) poolitavad talve. Kuna me ei saa südaööl jälgida päikese liikumist, on aasta koos pööripäevadega antud juhul päeva ja aasta analoogia A-teljest lähtuvas jaotuses selgemini avalduv. Ent see A-teljest lähtuv jaotus on veelgi ilmsem kuutsükli puhul, seetõttu kaasan nüüd arutelusse ka kuu. Ka kuutsükli puhul saame rakendada puhul B-teljest lähtuvat jaotust, arvestades, et kuu annab esimeses veerandis kõige rohkem ja viimases veerandis kõige vähem valgust, mis on vastavuses päeva ja öö ning suve ja talvega, kuid selgemini avaldub polaarsus kuutsükli kasvavate ja kahanevate poolte puhul, mille puhul jaotus lähtub Ateljest. See tähendab, et noorkuu kasvamine täiskuuks on vastavuses aasta selle poolega, millele on omane valgustugevuse kasvamine - talvisest pööripäevast suvise pööripäevani. Kuu kahanemine täiskuust vanaks kuuks aga on vastavuses aasta teise poolega - suvisest pööripäevast talvise pööripäevani. Esimene nimetatud perioodidest - valgustugevuse kasvamise periood jääb positiivsele poolele. Täiskuu on vastavuses aastaringi jaanipäevaga ja ööpäevatsükli keskpäevaga ning kuu peidusoleku periood on vastavuses jõulude ja südaööga.

Siinkohal arendan ma edasi N. Tolstoi tähelepanekuid ööpäevatsükli südaööjärgse perioodi ja aastaringi jõuludejärgse perioodi isomorfismi kohta. Kirikukalendris moodustab erilise perioodi jõuludeaegne kaksteistpäevak, mis 
kestab jõuludest (25. detsember) kolmekuningapäevani (6. jaanuar). Seda perioodi markeerivad tugevalt rituaalsed tegevused ning ühe laialt tuntud uskumuse järgi on nende kaheteistkümne päeva ilma jälgides võimalik prognoosida saabuva kaheteistkümne kuu ilma. See prognoos peab paika sõltumata sellest, millal täpselt need kaksteist päeva on, sest peab märkima, et rahvakalendritele on omane teatav paindlikkus. Näiteks olen ma kuulnud Maltal kasutatavast äärmiselt rikkalikust ja keerukast viisist saabuva aasta ilma ennustamiseks, mis lähtub kaheteistkümnest päevast, mille alguspunktiks on 13. detsember. ${ }^{3}$ Laiemalt võttes on tegemist talvise pööripäeva vahetus läheduses paikneva kaksteist päeva kestva perioodiga, mis jääb mõistagi talvisesse poolaastasse. Huvitaval kombel on slaavi kultuurist tõendeid selle kohta, et ka ööpäevatsükli ööpooles oli teatud periood, mida on mõnikord nimetatud "kurdiks ööks", samamoodi nagu kahtteistkümmet jõulujärgset päeva on vahel nimetatud "kurtideks päevadeks". See aeg kestis südaööst kukelauluni, st päikesetõusu esimeste valguskiirteni. Slaavi materjalis, mida N. Tolstoi oma väidete tõestusena kasutas, ei leidu mingit viidet viimastele valguskiirtele enne südaöö saabumist (päikeseloojangu markeeringuna), kuid olen väitnud (Lyle 2000), et täieliku pimeduse aeg, mis jääb viimaste valguskiirte kadumise ja esimeste valguskiirte ilmumise vahele, on vastavuses aastaringi kaksteistpäevakuga, kusjuures tähelepanu väärib ka tõik, et slaavi kultuuriruumis tajuti kaksteistpäevakut omakorda kaheks jagunevana - esiteks pühad õhtud ja seejärel hirmuäratavad õhtud -, nii et moodustub tasakaalustatud ajalõikude paar, mis on ühtlasi vastavuses ajalõikudega enne ja pärast südaööd, kuigi - nagu juba ütlesin - N. Tolstoil puudub viide asjaolule, et südaööeelset aega oleks kuidagi eriliselt määratletud. Ööpäevatsükli täieliku pimeduse aeg on vastavuses kuu peidusolemise perioodiga vanakuu kadumisest noorkuu ilmumiseni. Kuutsükli puhul avaldub teatud tühimiku tajumine väga tugevalt ning see näib olevat vastavuses surma tajumisega tühimikuna suremise ja sündimise vahel. Inimese eluringi uurimisel näib olevat vajalik tegelda nii tühjuse või nähtamatuse perioodi kui ka nähtavate eluperioodidega.

Eespool kirjeldasin suve ja päevapoolt (ning maksimaalse kuuvalguse perioodi) punase ning talve ja ööpoolt (ning minimaalse kuuvalguse perioodi) valgena, kuid nüüd näeme, et talvine poolaasta jaguneb kaksteistpäevaku tõttu omakorda kaheks, olles vastavuses täieliku pimeduse ja kuu peidusoleku perioodiga, ning kummalegi poole jääv osa on määratletav kevade- ja talveperioodiga (mõlemad jäävad talvisesse poolaastasse). Neile võib omistada erineva värvuse - kevadele valge ja talvele musta. Joonisel 1 on N. Tolstoi mainitud paarid esitatud nii B- kui ka A-teljel. Ära on näidatud ka A-teljele liidetud ja talvisesse poolaastasse jääv eriline periood ning noorkuu ja vanakuu märgivad vastavaid kuufaase. 


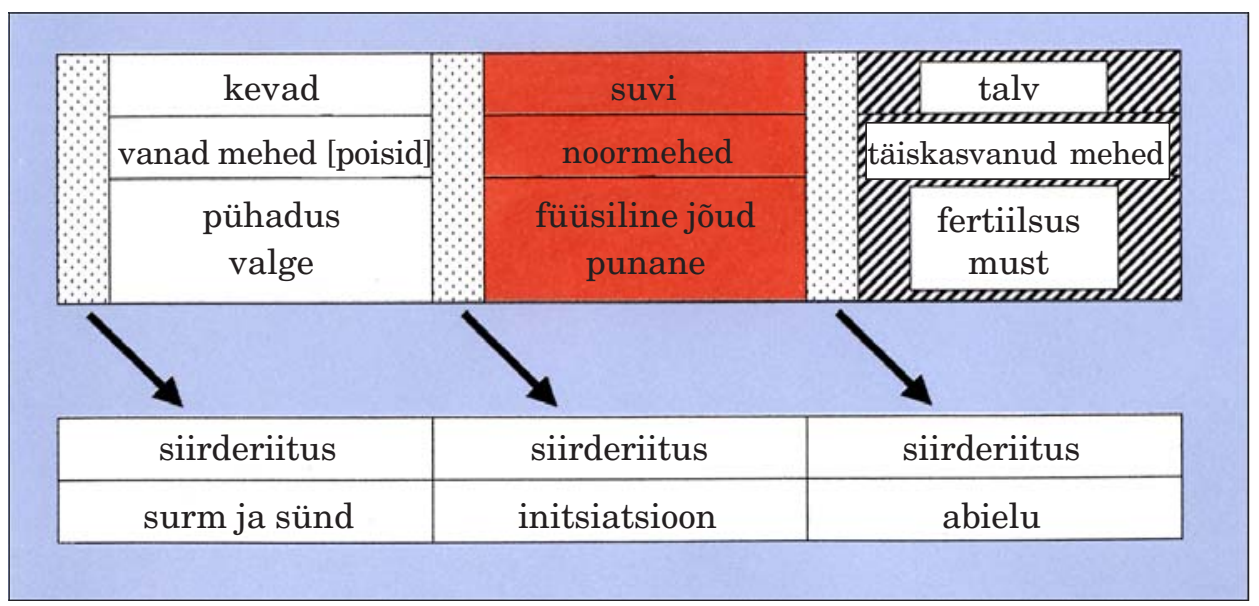

Joonis 2. Meeste üleminekud ühest staatusekategooriast teise (siirderiitused).

Talvise poolaasta must ja valge moodustavad triaadi suvise poolaasta punasega ning võimaldavad meil välja jõuda G. Dumézili süsteemini, mis on märkimisväärselt suur saavutus inimese eluringi puudutavate analoogiasarjade kohta. Räägin märkimisväärselt suurest saavutusest seetõttu, et Georges Dumézili teooriatel indoeuroopaliku kontseptuaalse ja sotsiaalse struktureerimise kohta on tundunud seni olevat vähe pistmist inimese eluringi valdkonnaga. Teema on keeruline ja ma ei saa sellesse siinkohal süvitsi laskuda, kuid olen välja pakkunud mõtte, mille teatavat arendust kohtasin esmakordselt iiri uurija Kim McCone'i töödes, nimelt et G. Dumézili funktsioonide triaad (s.o füüsiline jõud, õitseng ja pühadus) on vahetumalt seotud noorte meeste, täiskasvanud meeste ja vanade meeste elustaadiumidega kui tema poolt näidatud sõdalaste, põlluharijate ja preestrite sotsiaalsete rühmadega (Lyle 1997, 2004). Vastavalt sellele, kuidas mehed lülituvad seoses initsiatsiooniga staatusekategooriate süsteemi, jäävad noored poisid kõrvale, olles vanade meestega samal tasemel, sest süsteemi kulg läbi aja toob endaga kaasa vanade meeste väljavahetamise noortega, mis toimub kevadisel ajal, nagu võime näha jooniselt 2. Minu teooria kohaselt mõtestatakse ja tähistatakse üleminekut ühest elustaadiumist teise (surm ja sünd, initsiatsioon ja abielu) rituaalse aasta käigus (talvisel pööripäeval, suve alguses ja talve alguses). See teooria vajab aga kindlasti täiendavat uurimist ja testimist nii hiljutiste kui ka varasemate välitööde materjalide alusel.

Oma järeldustes ei saa ma mainimata jätta, et G. Dumézili triaad, mida väljendatakse valge, punase ja musta värvusega, näib mulle olevat põhiosas meessoost. Naissugu väljendatakse muul viisil -jagamatu ühtsusena, mis võib 
võtta kuninganna kuju; see on naise pulmapidu, mida peetakse veeranditeks jagatud aasta ühe veerandi lõpus ehk suvisel pööripäeval. Talve algust märgib samuti pulmapidu ja need kaks sündmust seovad kogukonda. Kaks ülejäänud üleminekupunkti talvisel pööripäeval ja suve alguses on konfliktse olemusega (neist mõlemast on ka etnoloogiakirjanduses piisavalt juttu olnud). Esimesele on omane surnute peletamine pärast karnevaliperioodi ja teisele võitlus talve ja suve vahel (Lyle 1990b, 2000).

Kirjeldatud analoogiad ei võimalda esitada terviklikku teooriat. Saame lähtuda sellest etalonsüsteemist ja lisada selliseid elemente nagu põllunduslikud ja karjakasvatuslikud tegevused, mis on sõltuvalt kliimast ja piirkonnast erinevad. Tegeldes konkreetsete juhtumitega saame neid sellegipoolest seostada etalonsüsteemiga ja erinevuste korral märkida neid lihtsalt erinevustena, ilma et peaksime tegema võib-olla ennatlikke järeldusi diakroonilise järjestuse ja sellest lähtuvalt ka süsteemi täiendamise vajaduste kohta. Usun, et meil on sellega käepärast väärtuslik heuristiline töövahend, mis võib uurijatele edaspidi rituaalset aastat käsitlevate uurimuste jätkamisel abiks olla.

Tõlkinud Reet Hiiemäe

\section{Kommentaarid}

${ }^{1}$ Käesolevas artiklis mainitud Vene kalendripühade daatumid on arvestatud juuliuse ehk vana kalendri järgi.

${ }^{2}$ Esmakordselt jõudis madude tähtsus markeritena aastajaotuses minu teadvusesse Galiitsias, kui Manolo Mandianes-Castro esitas oma ettekande "Le calendrier et le serpent en Galice (Espagne)" 20.-22. juunini 1993 peetud Traditsioonilise Kosmoloogia Seltsi konverentsil "Kalendrid”. Patricia Lysaght tegi oma tähelepaneku kahe päikese kohta Traditsioonilise Kosmoloogia Seltsi konverentsil "Aasta ja aastaaegade algused Edinburgh'is 3. märtsil 2001.

${ }^{3}$ Võlgnen tänu George Mifsud-Chircopile ja Tony Cardonale, kes minuga seda teemat arutasid.

\section{Kirjandus}

Lyle, Emily 1990a. Archaic Cosmos: Polarity, Space and Time. Polygon Cosmos. Edinburgh: Polygon.

Lyle, Emily 1990b. Winning and Losing in Seasonal Contests. Cosmos 6, lk 161-171.

Lyle, Emily 1997. Age Grades, Age Classes and Alternate Succession: A Restatement of the Basis at the Societal Level of Indo-European Symbolic Partition. Emania 16, lk 63-71 = Grades d'âge, classes d'âge et succession alternée: Nouvelles vues sur l'origine 
Emily Lyle

des partitions symboliques indo-européennes au niveau societal. Le Borgne, Aude (tõlk). Ollodagos 16 (2001), lk 111-145.

Lyle, Emily 2000. Interpreting Yule and Other Transitions in the Year. Cosmos 16, 151-158.

Lyle, Emily 2004. Which Triad? A Critique and Development of Dumézil's Trifunctional Theory. Revue de l'histoire des religions, lk 221, lk 5-21.

Mandianes-Castro, Manolo 2004. Le Magosto, fête des châtaignes et des morts en Galice. Bonnet, Jocelyne \& Fournier, Laurent Sébastien (toim). Fêtes et rites agraires en Europe: Métamorphoses. Collection Ethnologie de l'Europe. Paris \& Budapest \& Turin: L'Harmattan, lk 101-112.

Tolstoi 1997 = Толстой, Никита И. Времени магический круг. (по представлениям славян). Арутюнова, Нина Д. (toim). Ловический анализ языка: Язык и вреля. Москва: Индрик, lk 17-22.

Tolstoi, Nikita I. 2002 [ilmus 2005]. The Magic Circle of Time. Cosmos 18, lk 193-206.

\section{Summary}

\section{The question of the ritual year and the answers to it}

Emily Lyle

Key words: isomorphism, life cycle, lunar cycle, nychthemeron, ritual year, summer half, winter half

The author asks the question concerning the nature and identity of the ritual year. Other supplementary questions that can be asked are whether it is actually possible to locate an underlying coherence at all and, if so, what historical and geographical contexts would embrace it most fully. The author also inquires why there is no recognised current theory about the ritual year. In her approach she emphasises analogical thinking and takes the human life cycle as a key to the understanding of the patterning of the year. In the analysis, four levels are considered: whole eras or time itself at the large scale and with seconds or less at the small scale are dealt with, and the basic series of analogies has the human life cycle as the largest in scale and works down through the year and the month to the 24-hour day as the smallest. Thus, a reference set is established in which two tasks have to be considered: the first is to become familiar with the patterning of examples of the overall cyclical sequence, and the second is to categorise the divisions the cycle. The author has developed Tolstoy's observation concerning "the isomorphism of the periods after midnight in the diurnal circle and after Christmas in the year circle" and also the idea that Dumézil's triad of functions of physical force, prosperity and the sacred relates more fundamentally to the life stages of young men, mature men and old men than to the social groups he mentions of warriors, cultivators and priests. 